Yettie Wandansari : Dinamika coping stress wanita dewasa awal yang...

Hal. 11-19

\title{
EMOTION COACHING OLEH IBU PADA ANAK PRASEKOLAH
}

\author{
Yettie Wandansari \\ yettie@ukwms.ac.id
}

Fakultas Psikologi Universitas Katolik Widya Mandala Surabaya

\begin{abstract}
Abstrak
Masa usia dini merupakan periode kritis dalam rentang kehidupan manusia. Untuk itu, optimalisasi perkembangan pada usia dini perlu mencakup semua aspek, termasuk aspek emosi. Pada masa prasekolah, perkembangan emosi anak berkembang pesat, yaitu dalam pengetahuan emosi, ekspresi emosi, dan regulasi emosi. Orangtua, terutama ibu, berperan penting dalam perkembangan emosi anak, antara lain melalui emotion coaching. Mengacu pada teori meta emosi, emotion coaching meliputi kesadaran orangtua akan emosi diri dan emosi anak. Orangtua yang menerapkan emotion coaching mempersepsikan emosi negatif anak sebagai hal yang penting, peka terhadap kondisi emosi anak, menghargai emosi anak, dan menggunakan situasi emosional secara konstruktif. Dalam proses interaksi orangtua dan anak, reaksi orangtua tidak terlepas dari pengaruh nilai kultural. Namun demikian, riset tentang emotion coaching oleh orangtua dalam konteks Indonesia masih terbatas. Oleh karena itu, penelitian ini bertujuan untuk memperoleh gambaran emotion coaching pada ibu di Surabaya yang memiliki anak usia prasekolah. Subjek penelitian adalah 147 ibu yang memiliki anak usia 3-6 tahun dan bersekolah di Taman Bermain atau Taman Kanak-Kanak. Hasil penelitian adalah mayoritas ibu (92\%) menunjukkan emotion coaching pada tingkat rendah. Pembahasan hasil dikaitkan dengan kerangka kultural. Hasil penelitian ini dapat dikembangkan lebih lanjut, antara lain mengeksplorasi nilai-nilai kultur khas masing-masing etnis yang berkontribusi pada emotion coaching, mengembangkan model teoritis ataupun intervensi terhadap emotion coaching yang sesuai dengan konteks kultur di Indonesia.
\end{abstract}

Kata kunci: emotion coaching, ibu, anak prasekolah

\begin{abstract}
Early childhood is known as a critical period in the human life span. For this reason, optimization of early childhood development needs to be done in all aspects, including emotional aspects. In the preschool period, children's emotional development develops rapidly, namely in emotion knowledge, emotion expression, and emotion regulation. Parents, especially mothers, play an important role in child's emotional development, one of which is through emotion coaching. According to the parental meta-emotion theory, emotion coaching includes parents' awareness of their own emotions and children's emotions. Parents who apply emotion coaching perceive children's negative emotions as important, are sensitive to children's emotional conditions, respect children's emotions, and use emotional situations constructively. In the process of interaction between parents and children, parents' reactions cannot be separated from the influence of their cultural values. However, research on emotion coaching by parents in the Indonesian context is still limited. Therefore, this study aims to obtain an overview of emotion coaching for mothers in Surabaya who have preschool aged children. Subjects were 147 mothers of children aged 3-6 years who attend Playgroup/ Kindergarten. The results showed that the majority of mothers (92\%) showed a low level of emotion coaching.
\end{abstract}


The discussion is related to the cultural framework. The results of the research can be further developed, for example exploring the cultural values of each ethnicity that contribute to emotion coaching, building models or emotion coaching interventions that are appropriate to the cultural context for parents in Indonesia.

Keywords: emotion coaching, mother, preschooler

\section{Pendahuluan}

Masa usia dini dikenal sebagai periode yang sangat penting dalam rentang kehidupan manusia. Hal ini didasari perspektif neurosains yang menyatakan bahwa sembilan puluh persen dari otak berkembang di usia 3 tahun ertama (Nelson, O'Brien, Calkins, Leerkes \& Marcovitch, 2013). Perkembangan otak tersebut ditentukan oleh interaksi antara aspek biologis dan pengalaman, sehingga pengalaman sosial-emosional anak memiliki peran penting dalam pertumbuhan otaknya (Housman, 2017). Dengan demikian, optimalisasi perkembangan anak di masa usia dini perlu mencakup stimulasi pada berbagai aspek perkembangan secara holistik, tidak hanya mencakup aspek biologis, fisik-motorik, intelektual, moral, sosial, dan spiritual, namun juga aspek emosi.

Perkembangan emosi pada individu telah berlangsung sejak masa bayi. LaFreniere (2000) menjelaskan bahwa pada masa usia dini anak telah mengalami berbagai emosi. Seiring dengan berkembangnya kemampuan berpikir dan ketrampilan berbahasa anak, ia semakin memahami pengalaman emosi mereka maupun pengalaman emosi orang lain, serta mengalami perkembangan dalam ketrampilan regulasi emosi. Pada masa prasekolah, seiring dengan makin kompleksnya emosi anak serta meningkatnya tuntutan sosial maupun akademik, anak belajar tentang strategi regulasi emosi yang lebih tepat. Terkadang anak belum berhasil, dan disregulasi emosi seringkali menimbulkan masalah agresi dan kompetensi sosial pada anak (Denham, Ferrier, Howarth, Herndon \& Bassett,
2016). Kemampuan anak untuk mengelola emosi tidak terjadi secara otomatis, melainkan sangat dipengaruhi oleh pengalaman belajar dari lingkungannya (Joseph \& Strain, 2003).

Orangtua sebagai lingkungan terdekat anak berperan penting dalam perkembangan anak, termasuk dalam hal perkembangan regulasi emosinya. Salah satu peran orangtua adalah melalui emotion coaching atau pengajaran tentang emosi oleh orangtua terhadap anak. Diskusi emosi dan kualitas komunikasi mengenai emosi dalam sebuah relasi yang hangat dapat membantu anak untuk mengekspresikan emosi dengan baik (Wilson, Havighurst, \& Harley, 2012). Melalui diskusi dengan orangtua tentang emosi, anak terbantu untuk merefleksikan, menginterpretasi dan mengevaluasi penyebab dan konsekuensi dari emosinya (Denham, Bassett, \& Wyatt, 2015). Sejumlah hasil riset melaporkan pula bahwa emotion coaching berkorelasi dengan regulasi emosi yang lebih baik pada anak (Ornaghi, Pepe, Agliati, \& Grazzani, 2019; Wilson dkk, 2019) dkk, 2014;), termasuk pada anak dari keluarga yang memiliki risiko ekonomi maupun pada anak yang pernah mengalami trauma (Ellis, Alisic, Reiss, Dishion, \& Fisher, 2013).

Menurut teori parental meta-emotion yang dikemukakan Gottman, Katz, \& Hooven (1996), emotion coaching mencakup kesadaran orangtua terhadap emosi diri sendiri dan emosi anak. Orangtua yang menerapkan emotion coaching menyadari emosi yang dirasakan, mampu membicarakan emosi tersebut dengan cara yang baik, menyadari emosi yang dirasakan anak, dan membantu anak menghadapi emosinya, terutama emosi negatifnya. Mereka mempersepsi emosi negatif anak sebagai kesempatan untuk membangun 
kedekatan dengan anak, peka dan respek terhadap kondisi emosi anak, memanfaatkan momen emosional untuk mendengarkan anak, berempati dan membantu anak melabel emosi yang ia rasakan, membimbing anak untuk meregulasi emosinya, menetapkan batasan, serta mengajarkan ekspresi emosi yang tepat.

Dalam proses interaksi antara orangtua dan anak, reaksi orangtua tidak terlepas dari pengaruh nilai-nilai budaya yang diyakininya. Nilai-nilai budaya yang diyakini seseorang tidak hanya memengaruhi cara individu mengenali emosi, tetapi juga bagaimana ia mengekspresikan dan mengelola emosi dengan cara yang dapat diterima oleh lingkungan sekitar (Kurniawan \& Hasanat, 2010). Masyarakat Indonesia memiliki keterkaitan dengan kultur kolektivistik (budaya Timur), dimana emosi dikaitkan dengan kendali diri demi mendukung relasi yang harmonis dengan orang lain dan tercapainya tujuan kelompok (Halberstadt \& Lozada, 2011). Hal ini berbeda dengan pandangan kultur individualistik (budaya Barat) bahwa emosi merupakan hal yang bersifat pribadi dan subjektif, sehingga mendukung ekspresi emosi secara terbuka.

Selanjutnya, menurut Castro (2015), keyakinan orangtua bahwa emosi merupakan hal yang penting mengindikasikan adanya kesadaran dan penerimaan terhadap emosi. Orangtua yang yakin akan pentingnya emosi berarti yakin bahwa anak akan memperoleh manfaat dari pengalaman dan ekspresi emosi positif maupun emosi negatif, dan bahwa emosiemosi tersebut memberikan kesempatan bagi anak untuk belajar dan berkembang. Mereka juga akan menciptakan lingkungan yang ekspresif secara emosi, peka terhadap emosi anak, dan menerima emosi anak, sehingga anak berkesempatan untuk belajar cara mengekspresikan dan mengidentifikasi emosi dirinya dan emosi orang lain (Dunsmore, Her, Halberstadt, \& PerezRivera., 2009). Sebaliknya, orangtua yang mempersepsi emosi sebagai hal yang problematik atau berbahaya bila anak sering atau intens mengalaminya akan menutupi atau menyembunyikan emosi mereka, agar anak tidak melihat pengalaman emosi orangtua (Dunsmore dkk., 2009).

Berdasarkan penjelasan tersebut, maka dapat diketahui bahwa untuk memahami emotion coaching maka konteks kultur tidak dapat diabaikan. Sejauh yang diketahui penulis, data riset tentang emotion coaching pada kultur kolektivistik, khususnya di Indonesia, masih terbatas. Oleh karena itu, penelitian ini bertujuan untuk memperoleh gambaran mengenai emotion coaching pada para ibu di Surabaya yang memiliki anak usia prasekolah. Surabaya merupakan kota multikultur, oleh karena faktor sejarah yang panjang memiliki warga berlatarbelakang aneka etnis yang hidup rukun berdampingan (Soedarso, Nurif, \& Windiani, 2013). Hasil penelitian ini diharapkan dapat menstimulasi penelitian lanjutan untuk pengembangan model dan intervensi emotion coaching orangtua yang sesuai dengan konteks kultur di Indonesia.

\section{Emotion Coaching}

Menurut Halberstadt (dalam Denham, Mitchell-Coppeland, Stranberg, Auerbach, \& Blair, 1997), coaching hypothesis menyatakan bahwa cara orangtua mengajarkan emosi berkontribusi pada ekspresi emosi anak dan reaksi anak terhadap emosi teman sebayanya. Cara yang digunakan orangtua dapat dibedakan menjadi dua tipe. Tipe pertama yaitu orangtua sebagai "coach" (pelatih) yang menyadari emosi anak, terutama emosi negatif, dan membantu anak untuk mengalami dan meregulasi emosinya. Tipe kedua adalah orangtua sebagai "dismisser" (pembebas) yang ingin membantu namun mengabaikan pengalaman emosi anak. Mengajak anak berpartisipasi dalam diskusi tentang emosi pada dasarnya memberikan alat bantu bagi anak untuk mengelola emosi, sehingga regulasi emosi dapat ditransfer dari eksternal (orangtua menenangkan anak saat menangis) menuju 
internal (anak menenangkan dirinya sendiri).

Berdasarkan teori parental metaemotion yang dikemukakan Gottman dkk (1996), gaya pengasuhan emotion coaching mencakup kesadaran orangtua mengenai emosi diri sendiri dan emosi anak. Mereka menyadari emosi yang dirasakan, mampu membicarakan emosi tersebut dengan cara yang baik, menyadari emosi yang dirasakan anak, dan membantu anak menghadapi emosinya, terutama emosi negatifnya. Mereka menilai emosi negatif anak sebagai sebuah peluang untuk membangun kedekatan dengan anak, serta mampu bertoleransi atas waktu yang digunakan untuk menghadapi ketakutan, kemarahan, atau kesedihan anak, tanpa menjadi tidak sabar terhadap emosi-emosi tersebut. Mereka mempersepsi emosi negatif anak sebagai hal penting dalam pengasuhan anak, peka terhadap kondisi emosi anak, respek terhadap emosi anak, dan memanfaatkan situasi emosional secara konstruktif. Misalnya, mereka akan memanfaatkan momen emosional untuk mendengarkan anak, berempati pada anak dengan kata-kata yang menenangkan, membantu anak melabel emosi yang ia rasakan, membimbing anak untuk meregulasi emosinya, menetapkan batasan, dan mengajarkan ekspresi emosi yang tepat. Emotion coaching membantu anak untuk memahami bahwa semua emosi dapat diterima, mengajarkan batasan atau aturan dalam mengekspresikan emosi, serta membantu anak untuk mengembangkan strategi pengelolaan emosi (Rose, McGuire-Snieckus, \& Gilbert, 2015).

\section{Emosi dalam kerangka budaya (cultural framework)}

Menurut kerangka budaya individualisme-kolektivisme, terdapat perbedaan dalam pemaknaan emosi. Pada budaya kolektivistik, emosi dicirikan oleh kendali diri untuk mendukung relasi yang harmonis dengan orang lain dan tercapainya tujuan kelompok. Sebaliknya, pada budaya individualistik emosi dipandang bersifat unik pada masing-masing individu, ekspresi emosi yang terbuka didukung, dan emosi dipandang sebagai pengalaman subjektif dan interpersonal (Halberstadt \& Lozada, 2011).

Kerangka budaya yang juga relevan dengan emosi adalah kerangka budaya jarak kekuasaan (power distance). Menurut Hofstede (2001, dalam Halberstadt \& Lozada, 2011), budaya dengan jarak kekuasaan yang kuat mengakui adanya ketidaksetaraan dalam relasi sosial dan lebih menekankan nilai kepatuhan, hormat terhadap otoritas, dan patuh terhadap aturan. Sebaliknya, budaya dengan jarak kekuasaan yang kurang kuat lebih menekankan kesetaraan dalam relasi sosial, mendorong nilai demokratis, memungkinkan adanya dialog dalam hirarki kekuasaan. Jarak kekuasaan yang kuat mendorong orangtua untuk mendorong anak untuk patuh dan hormat pada orang lain serta menggunakan cara berkomunikasi satu arah dengan anak. Sedangkan jarak kekuasaan yang kurang kuat mendorong orangtua untuk berdialog dengan anak dan memberi kesempatan bagi anak untuk menyampaikan pendapatnya.

Berdasarkan penjelasan tersebut, dapat dipahami bahwa emosi berkaitan dengan kerangka kultur. Kerangka kultur yang berbeda memiliki persepsi yang berbeda pula terhadap emosi maupun terhadap cara orangtua berelasi dengan anak. Berdasarkan hal itu, maka penelitian ini bertujuan untuk memperoleh gambaran mengenai emotion coaching pada konteks Indonesia.

\section{Metode Penelitian}

Metode dalam penelitian ini adalah metode deskriptif kuantitatif. Variabel penelitian adalah emotion coaching oleh ibu. Partisipan berjumlah $147 \mathrm{ibu}$ yang memiliki anak usia 3-6 tahun dan bersekolah di Taman Bermain dan Taman Kanak-kanak di Surabaya. Pemilihan sekolah dilakukan secara purposif, yaitu memenuhi kriteria memiliki siswa usia 3-6 tahun, orangtua bersedia berpartisipasi 
dalam penelitian, dan pihak sekolah mengijinkan pengambilan data di sekolah tersebut.

Emotion coaching oleh ibu diukur dengan menggunakan sub-skala Coaching dalam Maternal Emotional Styles Questionnaire (MESQ, Lagace-Seguin \& Coplan, 2005). Skala terdiri atas 7 aitem dengan lima pilihan jawaban (sangat tidak setuju, tidak setuju, netral, setuju, sangat setuju). Contoh aitem misalnya saat anak saya marah, saya meluangkan waktu bersamanya untuk mencoba menyelami perasaannya. Contoh aitem lain, ketika anak saya sedih maka itu adalah waktu yang tepat untuk mendekatinya. Skala diterjemahkan melalui proses forward translation dan back translation. Ibu mengisi secara mandiri skala dalam bentuk hard-copy.

Data dianalisis dengan menggunakan analisis deskriptif dengan bantuan program SPSS 20. Analisis deskriptif mencakup gambaran emotion coaching ibu berdasarkan skoring kuesioner dan melihat perbedaan emotion coaching ibu berdasarkan data demografis yaitu usia anak, jender anak, dan status kerja ibu.

\section{Hasil dan pembahasan}

\section{Deskripsi Data Variabel Penelitian}

Penelitian dilakukan pada 147 pasang ibu dan anak usia 3-6 tahun yang bersekolah di Taman Bermain/Taman Kanak-Kanak di kota Surabaya. Deskripsi demografi sampel penelitian terdiri atas deskripsi usia anak, jender anak, dan status kerja ibu. Deskripsi usia subjek dapat diketahui dari Tabel 1 berikut ini.

Tabel 1. Karakteristik Subjek

\begin{tabular}{|c|c|c|c|c|c|}
\hline Karakteristik & Kategori & Frekuensi & $\%$ & Total & $\%$ \\
\hline \multirow{4}{*}{ Usia Anak } & 3 tahun & 7 & 4.8 & \multirow[t]{4}{*}{147} & \multirow[t]{4}{*}{100} \\
\hline & 4 tahun & 51 & 34.7 & & \\
\hline & 5 tahun & 60 & 40.8 & & \\
\hline & 6 tahun & 29 & 19.7 & & \\
\hline \multirow[t]{2}{*}{ Jender Anak } & Perempuan & 70 & 47.6 & \multirow[t]{2}{*}{147} & \multirow[t]{2}{*}{100} \\
\hline & Laki-laki & 77 & 52.4 & & \\
\hline \multirow{3}{*}{$\begin{array}{l}\text { Status } \\
\text { Ibu }\end{array}$} & a Tidak bekerja & 91 & 61.9 & \multirow[t]{3}{*}{147} & \multirow[t]{3}{*}{100} \\
\hline & Bekerja & 53 & 36.1 & & \\
\hline & Tidak menjawab & 3 & 2 & & \\
\hline
\end{tabular}

Berdasarkan data pada Tabel 1 dapat diketahui bahwa sebaran usia anak adalah antara usia 3-6 tahun, dengan jumlah terbanyak usia 5 tahun (41\%) dan 4 tahun (35\%). Rasio anak laki-laki dan perempuan cukup berimbang, yaitu anak laki-laki berjumlah $48 \%$ dan anak perempuan berjumlah 52\%. Jumlah ibu tidak bekerja (62\%) lebih banyak daripada ibu bekerja $(36 \%)$.

Tabel 2.

Perbandingan Data Empirik dan Data Hipotetik Emotion Coaching

\begin{tabular}{|c|c|c|c|c|c|c|c|c|c|}
\hline \multirow[t]{3}{*}{ Variabel } & \multirow[t]{3}{*}{$\mathrm{N}$} & \multicolumn{4}{|c|}{ Data Empirik } & \multicolumn{4}{|c|}{ Data Hipotetik } \\
\hline & & \multirow[t]{2}{*}{ Mean } & \multicolumn{2}{|l|}{ Skor } & \multirow[t]{2}{*}{ SD } & \multirow[t]{2}{*}{ Mean } & \multicolumn{2}{|c|}{ Skor } & SD \\
\hline & & & Min & Max & & & Min & Max & \\
\hline $\begin{array}{l}\text { Emotion } \\
\text { coaching ibu }\end{array}$ & 147 & 14 & 8 & 20 & 2,0 & 21 & 7 & 35 & 4,7 \\
\hline
\end{tabular}


Data pada Tabel 2 menunjukkan bahwa variabel emotion coaching ibu menunjukkan rerata skor empiris di bawah rerata skor hipotetik.

Tabel 3.

Prosentase Profil Emotion Coaching Ibu

\begin{tabular}{llllllllllllll}
\hline \multirow{2}{*}{ Variabel } & \multicolumn{3}{l}{ Kategori } & $\begin{array}{l}\text { Sangat } \\
\text { Rendah }\end{array}$ & Rendah & Sedang & Tinggi & $\begin{array}{l}\text { Sangat } \\
\text { Tinggi }\end{array}$ & Total \\
& n & $\%$ & $\mathrm{f}$ & $\%$ & $\mathrm{~F}$ & $\%$ & $\mathrm{~F}$ & $\%$ & $\mathrm{~F}$ & $\%$ & $\mathrm{~F}$ & $\%$ \\
\hline $\begin{array}{l}\text { Emotion } \\
\text { coaching ibu }\end{array}$ & 34 & 23 & 102 & 69 & 11 & 8 & 0 & 0 & 0 & 0 & 147 & 100 \\
\hline
\end{tabular}

Berdasarkan data pada Tabel 3, dapat diketahui bahwa pada data emotion coaching ibu, mayoritas subjek (92\%) menunjukkan skor pada kategori rendah dan sangat rendah. Sebaran data terkumpul pada kategori rendah dan sangat rendah, tanpa ada skor pada kategori tinggi dan sangat tinggi.

\section{Uji Validitas dan Reliabilitas Instrumen}

Uji validitas pada Maternal Emotional Styles Questionnaire (MESQ) sub-skala coaching menunjukkan hasil semua aitem valid (7 aitem), dengan rentang nilai corrected item-total correlation antara 0,368 sampai 0,650 ( >r tabel 0,176). Koefisien reliabilitas Alpha Cronbach sebesar 0,780 (reliabilitas cukup baik).

\section{Uji asumsi}

Hasil uji normalitas data emotion coaching melalui uji Kolmogorov-Smirnov menunjukkan nilai $z=0,000(p<0.05)$, atau data tidak berdistribusi normal. Oleh karena data tidak normal, maka untuk menguji perbedaan emotion coaching ibu berdasarkan data demografis (jenis kelamin anak, usia anak, dan status kerja ibu) digunakan uji non-parametrik Mann Whitney $U$ test. Tiga asumsi yang harus terpenuhi untuk menggunakan Mann Whitney U test, yaitu data tidak normal, data berasal dari 2 kelompok yang berbeda, dan varians kedua kelompok sama atau homogen. Ketiga asumsi tersebut telah terpenuhi.

\section{Deskripsi emotion coaching ibu berdasarkan data demografis}

Untuk perbedaan emotion coaching ibu berdasarkan jenis kelamin anak, hasilnya adalah sebagai berikut. Data mean rank atau rata-rata peringkat menunjukkan bahwa rerata peringkat emotion coaching ibu terhadap kelompok anak laki-laki lebih tinggi daripada terhadap kelompok anak perempuan. Hasil uji Mann-Whitney U menunjukkan nilai $p=0,810(>0,05)$, artinya perbedaan antara kedua kelompok tersebut tidak signifikan.

Untuk perbedaan emotion coaching ibu berdasarkan usia anak, hasilnya adalah sebagai berikut. Rerata peringkat tertinggi adalah pada emotion coaching ibu terhadap kelompok anak usia 3 (85), diikuti kelompok usia 5 tahun $(79,14)$, kelompok usia 4 tahun $(69,25)$, dan terakhir kelompok usia 6 tahun $(69,05)$. Selanjutnya digunakan uji Kruskal Wallis karena terdapat 4 kelompok usia anak (lebih dari 2 kelompok). Hasilnya menunjukkan nilai $p=, 494(>0,05)$, artinya perbedaan emotion coaching ibu terhadap keempat kelompok usia anak tidak signifikan.

Untuk perbedaan emotion coaching ibu berdasarkan status kerja ibu, hasilnya adalah sebagai berikut. Rerata peringkat kelompok ibu tidak bekerja (6492) lebih tinggi daripada kelompok ibu bekerja (3948). Hasil uji Mann-Whitney U menunjukkan nilai $p=0,660(>0,05)$, artinya perbedaan emotion coaching antara kelompok ibu tidak bekerja dan kelompok ibu bekerja tidak signifikan. 


\section{Pembahasan}

Data deskriptif menunjukkan bahwa 92\% ibu memiliki tingkat emotion coaching yang rendah. Tidak ada ibu yang memiliki tingkat emotion coaching tinggi. Artinya, mayoritas ibu jarang atau bahkan tidak menerapkan emotion coaching terhadap anak. Hal ini terjadi baik pada anak laki-laki maupun perempuan, pada anak usia 3 sampai 6 tahun, serta pada ibu bekerja maupun tidak bekerja.

Apabila jawaban pada aitem-aitem skala dicermati, rendahnya emotion coaching pada mayoritas subjek dalam penelitian ini mengindikasikan adanya persepsi mayoritas ibu bahwa momen saat anak sedih atau marah bukan merupakan kesempatan untuk mendekati anak, meluangkan waktu bersama anak untuk mencoba menyelami perasaannya, ataupun mengajarkan pada anak cara menyelesaikan masalah.

Peneliti tidak melakukan wawancara terhadap subjek, sehingga tidak memiliki cukup data untuk menjelaskan penyebab rendahnya tingkat emotion coaching tersebut. Di antara beberapa riset yang relevan dan menggunakan partisipan orang Indonesia, salah satu yang paling mendekati adalah penelitian Irene dan Hendriati (2017) mengenai meta-emosi pada guru anak usia dini di Jakarta. Penelitian tersebut memberikan gambaran bahwa kultur kolektivistik yang mengutamakan harmoni dalam relasi sosial turut berpengaruh pada rendahnya emotion coaching pada guru, terutama dalam kaitannya dengan emosi negatif siswa. Secara kultural, emosi negatif dipersepsikan sebagai hal yang dapat mengganggu harmoni dalam relasi dengan orang lain, sehingga cenderung dihindari atau ditekan, dan tidak didiskusikan maupun diajarkan pada anak.

Nilai kultur kolektivistik yang mengutamakan interdependensi dan harmoni sosial merupakan konteks yang relevan untuk menjelaskan rendahnya penerapan emotion coaching para ibu dalam penelitian ini. Sebagaimana ditegaskan Bowie, Carrère, Cooke, Valdivia,
McAllister, \& Doohan (2011) bahwa kultur dan etnis memengaruhi keyakinan, nilai, dan perilaku dalam keluarga, apapun latar belakang kultur mereka. Adanya persepsi kultural terhadap emosi negatif sebagai hal yang perlu dihindari atau ditekan demi menjaga relasi dengan orang lain dapat mempengaruhi cara ibu dalam pengajaran tentang emosi pada anak. Dengan perspektif tersebut, maka beberapa kemungkinan yang dapat terjadi saat ibu menghadapi emosi anak adalah ibu akan membatasi, meminimalkan, bahkan menghindari pembicaraan tentang emosi negatif dengan anak, atau mengajarkan pada anak untuk menghindari atau menekan emosi agar tidak mengganggu keharmonisan relasi dengan orang lain.

Selain perspektif individualismekolektivisme, kerangka kultur yang lain adalah jarak kekuasaan (power distance). Mengacu pada pernyataan Hofstede (2001, dalam Halberstadt \& Lozada, 2011), budaya dengan jarak kekuasaan yang kuat mengakui adanya ketidaksetaraan dalam relasi sosial dan lebih menekankan nilai kepatuhan, hormat terhadap otoritas, dan patuh terhadap aturan. Sebaliknya, budaya dengan jarak kekuasaan yang kurang kuat lebih menekankan kesetaraan dalam relasi sosial, mendorong nilai demokratis, memungkinkan adanya dialog dalam hirarki kekuasaan. Dalam kaitan dengan emotion coaching yang terarah pada terbangunnya diskusi interaktif dan dialogis antara orangtua dan anak mengenai emosi, maka kultur masyarakat Barat lebih demokratis mendukung orangtua untuk berdialog dan memberi kesempatan bagi anak untuk menyampaikan pendapatnya. Hal ini sejalan atau mendukung penerapan emotion coaching oleh orangtua terhadap anak. Sebaliknya, pada kultur masyarakat Timur terdapat jarak kekuasaan yang kuat (antara orangtua dan anak), sehingga orangtua lebih mendorong anak untuk patuh dan hormat pada orangtua, serta menggunakan cara berkomunikasi satu arah dengan anak.

Mengacu pada dua kerangka kultur tersebut, maka rendahnya emotion coaching 
pada subjek penelitian ini kemungkinan terkait dengan perspektif kultur pada masyarakat Timur yang cenderung berkebalikan dengan indikator emotion coaching. Ciri-ciri emotion coaching menurut Gottman dkk (1996) adalah menerima emosi sebagai hal penting, dan bahwa anak akan memperoleh manfaat dari pengalaman dan ekspresi emosi, baik emosi positif maupun emosi negatif. Pengalaman emosi dinilai sebagai kesempatan bagi anak untuk belajar dan berkembang. Orangtua yang menilai emosi positif maupun emosi negatif sebagai hal penting akan menciptakan lingkungan yang ekspresif secara emosi, peka terhadap emosi anak, dan menerima emosi anak. Jadi, persepsi atau penilaian terhadap emosi anak (yang dilandasi perspektif kultur) akan menentukan penerapam emotion coaching terhadap anak. Dalam penelitian ini, mayoritas para ibu menunjukkan persepsi yang kurang mendukung emosi negatif anak, sehingga tingkat emotion coachingnya menjadi rendah.

Hasil penelitian ini tidak terlepas dari beberapa keterbatasan. Pertama, metode yang digunakan adalah kuesioner, tidak dilengkapi dengan wawancara. Kedua, subjek hanya merepresentasikan sebagian kecil populasi penelitian. Ketiga, penelitian dibatasi pada emotion coaching oleh ibu saja, tidak melibatkan ayah atau guru yang juga memiliki peran penting dalam perkembangan emosi anak.

\section{Simpulan}

Mayoritas ibu (92\%) dalam penelitian ini menunjukkan tingkat emotion coaching yang rendah. Tidak ada ibu yang menunjukkan tingkat emotion coaching yang tinggi. Bagi penelitian lanjutan, hasil penelitian ini dapat ditindaklanjuti dengan menerapkan multi-method dalam pengukuran, memperbesar jumlah partisipan, serta melibatkan ayah dan guru sebagai pelaku emotion coaching. Hasil penelitian ini dapat dikembangkan lebih lanjut, misalnya mengeksplorasi nilai-nilai kultur masing-masing etnis yang berkontribusi pada emotion coaching, membangun model maupun intervensi emotion coaching yang sesuai dengan konteks kultur bagi orangtua di Indonesia.

\section{Referensi}

Bowie, B. H., Carrère, S., Cooke, C., Valdivia, G., McAllister, B., \& Doohan, E. (2011). The role of culture in parent's socialization of children's emotional development. Western Journal of Nursing Research, 35, 514. Doi: 10.1177/0193945911411494.

Castro, V.L., Halberstadt, A.G., Lozada, F.T., \& Craig, A.B. (2015). Parents' emotion-related beliefs, behaviors, and skills predict children's recognition of emotion. Infant \& Child Development, 24 (1), 1-22. Doi:10.1002/icd.1868.

Denham, S.A., Bassett, H.H., \& Wyatt, T. (2007). The socialization of emotional competence. Dalam J. Grusec \& P. Hastings (eds). The Handbook of Socialization (pp. 614637). New York: Guilford..

Denham, S.A., Ferrier, D.E., Howarth, G.Z., Herndon, K.J., \& Bassett, H.H. (2016). Key considerations in assessing young children's emotional competence. Cambridge Journal of Education, 46 (3), 299-317. http://dx.doi.org/10.1080/ 0305764X.2016.1146659.

Denham, S.A., Mitchell-Coppeland, J., Stranberg, K., Auerbach, S., \& Blair, K. (1997). Parental contributions to preschoolers' emotional competence: Direct and indirect effects. Motivation and Emotion, 21 (1), 6586.

Dunsmore, J.C., Her, P., Halberstadt, A.G., \& Perez-Rivera, M.B. (2009). Parents' beliefs about emotions and children's recognition of parents' emotion. Journal of Nonverbal Behavior, 33 (2), 121-140. 
Ellis, B.H., Alisic, E., Reiss, A., Dishion, T., \& Fisher, P.A. (2013). Emotion regulation among preschoolers on a continuum of risk: The role of maternal emotion coaching. Journal of Child and Family Studies,23 (6), 965-974. Doi: 10.1007/s10826-0139752-z.

Gottman, J.M., Katz, L.F., \& Hooven, C. (1996). Parental meta-emotion philosophy and the emotional life of families: Theoretical models and preliminary data. Journal of Family Psychology, 10 (3), 243-268.

Halberstadt, A.G., \& Lozada, F.T. (2011). Emotion development in infancy through the lens of culture. Emotion Review, 3 (2), 158-168.

Housman, D.K. (2017). The importance of emotional competence and selfregulation from birth: a case for the evidence-based emotional cognitive social early learning approach. International Journal of Child Care and Education Policy, 1-19. Doi: 10.1186/s40723-017-0038-6.

Irene, J., \& Hendriati, A. (2017). Emotion coaching by preschool teachers in Jakarta. Proceeding. Dipresentasikan dalam International Conference on Psychology and Multiculturalism. Jakarta: Atma Jaya Catholic University of Indonesia.

Joseph, G.E., \& Strain, P.S. (2003). Comprehensive evidence-based social-emotional curricula for young children: An analysis of efficacious adoption potential. Topics in Early Childhood Special Education, 23 (2), 65-76.

Kurniawan, A.P., \& Hasanam N.U. (2010). Ekspresi emosi pada tiga tingkatan perkembangan pada suku Jawa di Yogyakarta: Kajian psikologi emosi dan kultur masyarakat Jawa. Jurnal Psikologi Indonesia, 7 (1), 50-64.

LaFreniere, P. (2000). Emotional development, A biosocial perspective.
Belmont, California:

Wadsworth/Thompson Learning.

Lagace-Seguin, D., \& Coplan, R.J. (2005).

Maternal emotional styles and child social adjustment: Assessment, correlates, outcomes and goodness of fit in early childhood. Social Development, 14 (4), 613-636.

Nelson, J., O'Brien, M., Calkins, S.D., Leerkes, E.M., \& Marcovitch, S. (2012). Maternal expressive style and children's emotional development. Infant \& Child Development, 21 (3), 267-286.

Ornaghi, V., Pepe, A., Agliati, A., \& Grazzani, I. (2019). The contribution of emotion knowledge, language ability, and maternal emotion socialization style to explaining toddlers' emotion regulation. Social Development, 28 (3), 581-598. https://doi.org/10.1111/sode.12351.

Rose, J., Gilbert, L., McGuire-Snieckus, R. (2015). Emotion coaching a strategy for promoting behavioral selfregulation in children/young people in schools: A pilot study. The European Journal of Social \& Behavioral Sciences, 13, 1766-1790.

Soedarso, Nurif, M., \& Windiani (2013). Dinamika multikultural masyarakat Kota Surabaya. Jurnal Sosial Humaniora, 6 (1), 62-75.

Wilson, K.R., Havighurst, S.S., \& Harley, A.E. (2012). Tuning in to kids: An effectiveness trial of a parenting program targeting emotion socialization of preschoolers. Journal of Family Psychology, 26 (1), 56-65.

Wilson, B.J., Petaja, H., Yun, J., King, K., Berg, J., Kremmel, L., \& Cook, D. (2014). Parental emotion coaching: Associations with self-regulation in aggressive/rejected and low aggressive/popular children. Child and Family Behavior Therapy, 36 (2): 81-106. doi:10.1080/07317107.2014.910731. 